\title{
Using the Duolingo Tool to Support English Classes: Intervention and Experience
}

\author{
Claudio V. A. de Carvalho, Drayon R. M. D. Silva, Antonio C. Soares, Thereza P. P. Padilha, Pasqueline D. Scaico \\ Centro de Ciências Aplicadas e Educação - Universidade Federal da Paraíba \\ \{claudio.victor, drayon.richard, antonio.carlos, thereza, pasqueline\}@dcx.ufpb.br
}

Keywords: Educational technology; English learning; Duolingo.

Introduction: Several studies show that most students believe that their learning might be improved by integrating technology into classrooms [1][2]. Currently, there are several types of educational tools that can be use in the teachinglearning process, such as Kahoot!, ClassDojo, and Google Classroom. In addition, there are other more specific resources that can help to explore a certain subject more deeply. This abstract relates a pedagogical and technological intervention carried out by a group of students who attend an undergraduate program in computer science teaching. In order to support the English classes of a Brazilian high school, localized in Mamanguape city, Paraiba, they performed instructional activities focused on presenting a new learning and motivational resource. Methodology: Initially, the entire school was observed. Students, faculty, and staff were interviewed. While gathering some initial data, the researchers learned from the 12 th grade students about their struggles with comprehending English. Also, because English is one of the mandatory courses for those who apply for the National Secondary Education Examination (ENEM), an exam to be taken by students finishing their senior year who intend to enter most Brazilian universities, the 12th class was chosen for further study. Duolingo was selected as the central learning resource because it is the most popular software to support second language education (used by more than 300 million learners), it is free, and, mainly, it is a technology that runs in smartphones [3]. In total, 36 students participated in this study using Duolingo. To evaluate how the use of Duolingo might have impacted students' learning, a set of activities was developed based on a digital game. The logic is as follows: after some tips were presented to students, they had to figure out what word was being formed (Figure 1). As an example, a house and a bed that appear on the screen are the tips to identify the word WAKE UP. Discussion: According to the high school's English teacher, students who spent a great deal of time using Duolingo increased participation in classes. As Duolingo was installed in their smartphones, it can be credited for the increased participation. About the activities, most of the students assessed and utilized them to fix some words learned through Duolingo, such as verbs. Conclusions: This intervention was an excellent practical experience for future teachers because it was possible to follow up closely the learning process of students. Therefore, it reinforces the potential of technology to have a positive effect on knowledge acquisition. We believe that Duolingo might make learning more interesting, pleasant, and interactive in English classes as [4] as well. Furthermore, online tools increase the motivation to learn, especially in public schools where there are, unfortunately, fewer resources.

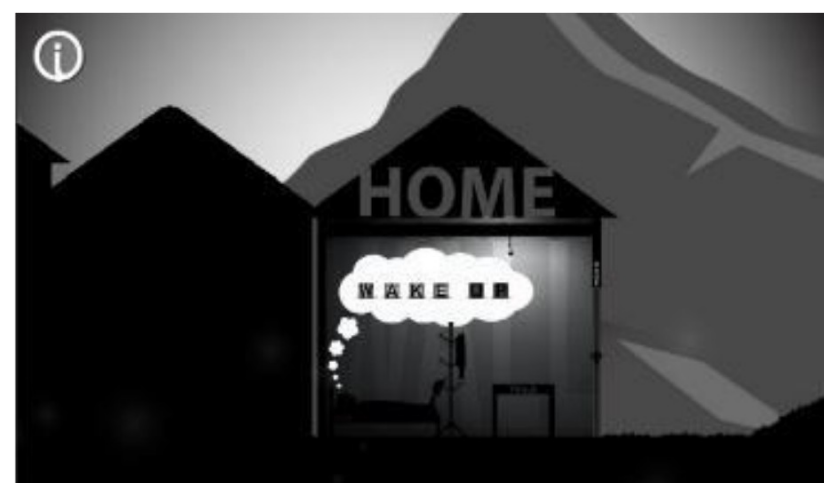

Figure 1:Example of applied activity.

\section{References}

[1] Costley, Kevin C. (2014) The Positive Effects of Technology on Teaching and Student Learning. Institute of Education Sciences, n. 554557.

[2] Baytak, A., Tarman, B., \& Ayas, C. (2011) Experiencing technology integration in education: children's perceptions. International Electronic Journal of Elementary Education 3(2): 139-151.

[3] Duolingo. Available in:https://www.duolingo.com. Access in Oct, 302019.

[4] Nushi, M.; Eqbali, M. H. (2017). Duolingo: A Mobile Application to Assist Second Language Learning. Teaching English with Technology 17(1): 89-98. 